\title{
Different aetiologies in male and female osteoporosis in Northern Ireland
}

\author{
David J. Armstrong ${ }^{1} \cdot$ Rhonda Hunter ${ }^{1}$
}

Received: 15 September 2016 / Accepted: 28 September 2016/Published online: 8 October 2016

(C) International Osteoporosis Foundation and National Osteoporosis Foundation 2016

\section{Dear Editor,}

We read with interest the article by Karayiannis and McAlinden on the incidence of hip fracture in Northern Ireland (NI), and noted the authors' speculation on the causes of the fall in female fractures, compared with the lack of change in males [1].

We run a fracture liaison service (FLS) at one of the four hospitals in NI which receive hip fractures, and believe the rolling out of FLS across NI over the last 10 years is one factor likely to have contributed significantly to the reduced incidence of new fractures in women, as it has been shown to do in other parts of the UK [2]. In addition, figures from our clinic show that men made up 80 out of 275 (29.1\%) consecutive patients between the ages of 50 and 75 seen for FLS assessment having sustained a low trauma fracture over a 6month period in 2015 . Of these, some $36.3 \%$ consumed alcohol at more than the government's recommended weekly limit, most being alcohol dependent. This contrasts with only $7.1 \%$ of females. Although the area in which we work has high levels of social deprivation, alcohol abuse is only one example of how the aetiology of male osteoporosis is often very different from post-menopausal female osteoporosis, and that a completely different approach, including societal changes, may be necessary to address the condition in men, if a similar fall in incidence is to be seen.

Compliance with ethical standards

Conflicts of interest None.

\section{References}

1. Karayiannis PN, McAlinden MG (2016) Falling age-related incidence of hip fractures in women, but not men, in Northern Ireland: 2001-2011. Osteoporos Int. doi:10.1007/s00198-016-3677-5

2. McLellan AR, Wolowacz SE, Zimovetz EA et al (2011) Fracture liaison services for the evaluation and management of patients with osteoporotic fracture: a cost-effectiveness evaluation based on data collected over 8 years of service provision. Osteoporos Int 22:2083
David J. Armstrong

David.armstrong@westerntrust.hscni.net

1 Fracture Liaison Service, Altnagelvin Area Hospital, Glenshane Road, Londonderry, Northern Ireland, UK BT47 6SB 